\title{
LIDERANÇA E GESTÃO ESTRATÉGICA DE PESSOAS: DUAS FACES DA MESMA MOEDA
}

\author{
Leadership and strategic people management: \\ two faces of the same coin
}

\author{
Martinho Isnard Ribeiro de Almeida ${ }^{1}$ \\ Marcos Bidart Carneiro de Novaes ${ }^{2}$ \\ Celso Likio Yamaguti ${ }^{3}$
}

\section{Resumo}

Este artigo analisa e discute como a questão da liderança está inserida nas reflexões estratégicas de uma companhia de seguros de grande porte em atuação no Brasil. Ao longo do artigo são apresentados alguns dos principais modelos de gestão estratégica de ativos intangíveis, bem como modelos específicos sobre liderança que buscam quantificar a mesma para uso no desenvolvimento de pessoas. Conclui-se que ainda não há clareza na organização estudada sobre como validar os treinamentos realizados para a formação de líderes e como desenvolver estes cursos e pessoas para alinhamento com as estratégias organizacionais. Apesar da aparente importância que este desenvolvimento pode ter para apoiar as políticas de gestão de pessoas em andamento na empresa. Intelectual.

Palavras-chave: Liderança; Gestão de Pessoas; Estratégia; Ativos Intangíveis; Capital

\footnotetext{
Abstract

This article analyses and discusses how the issue of leadership is contained in the strategic reflections of a major insurance company in Brazil. It presents the main models of

${ }^{1}$ Professor Livre Docente, Faculdade de Economia e Administração da Universidade de São Paulo (FEA-USP), Av. Prof. Luciano Gualberto, 908 - 05508-900 - São Paulo, SP, Brasil. E-mail: martinho@usp.br

${ }^{2}$ Mestrando em Administração de Empresas, Universidade Municipal de São Caetano, Av. Goiás, 3 - 400 - 09550 051 - São Caetano do Sul, SP, Brasil. E-mail: bidart@uol.com.br

${ }^{3}$ Doutorando em Administração, Faculdade de Economia e Administração da Universidade de São Paulo (FEA-USP), Av. Prof. Luciano Gualberto, 908 - 05508-900 - São Paulo, SP, Brasil. E-mail: celso@usp.br
} 
intangible assets management, as well as specific models which aim to quantify leadership, to be used in people development. The authors conclude that it is not clear how leader training courses can be validated in the organization studied and how those courses and people can be developed for alignment with the strategies of the company. Notwithstanding the importance that this development may have for supporting the people management policies being put in practice by the organization. Capital.

Keywords: Leadership;, People Management; Strategy;, Intangible Assets; Intellectual

\section{Introdução}

Até o início dos anos 1990, o principal sistema de avaliação das empresas ainda era exclusivamente o da contabilidade financeira. Este não fornecia fundamentos para a mensuração e gestão do valor criado pelos ativos intangíveis da organização (KAPLAN e NORTON, 2004a). Passou-se, então, a aceitar que esses ativos "escondidos", tais como relacionamento com clientes, fidelidade a marcas, posicionamento de mercado, qualidade de processos e a liderança, no sentido de gestão da mudança e transformação organizacional, dizem mais sobre as capacidades futuras de geração de valor de uma empresa do que medidas convencionais de desempenho, como o potencial de crescimento (ROOS e ROOS, 1997). Entre os ativos intangíveis que podem existir em uma organização, o patrimônio da companhia baseado no conhecimento é o que melhor explica a questão da diferença entre o valor contábil e o valor de mercado de organizações (BRENNAN e CONNELL, 2000).

Nessa perspectiva, é crescente a importância do processo de formação de líderes eficientes e eficazes em uma organização, para proporcionar um ambiente fértil ao desenvolvimento do capital intelectual. Pesquisa feita com 312 executivos, nos Estados Unidos da América, levantou que $70 \%$ dos respondentes consideravam liderança como o ativo intangível mais importante e urgente em relação à questão de gestão de pessoas em suas organizações (ULRICH et al., 1999). Desenvolveram-se novos conceitos de liderança, que passaram a dar a devida importância a este gestor-líder, uma vez que não é mais possível planejar e organizar o trabalho de seres humanos como se fosse um problema de engenharia. Já não são mais adequadas relações entre líderes e liderados baseadas apenas na hierarquia tradicional e em relações contratuais de chefia e subordinação. A mera imposição de autoridade para lidar com conflitos não é mais adequada (KOUZES e POSNER, 1994).

O objetivo deste artigo é analisar e discutir como a questão da liderança está inserida nas reflexões estratégicas de uma companhia de seguros de grande porte em atuação no Brasil e como sua mensurabilidade é avaliada.

O trabalho versa sobre a liderança nas organizações e não das organizações. Não se discute aqui a importância do estilo do principal executivo, com autoridade formal para influenciar aspectos específicos do comportamento dos funcionários (WRIGHT et al., 2000), mas a questão da liderança em todos os níveis da empresa e suas relações com estratégias. Processos de liderança são criados e dirigidos nas organizações para definir, estabelecer, identificar e 
traduzir a missão e visão organizacional em uma direção para ação coletiva (ZACCARO e KLIMOSKI, 2001).

Este artigo se justifica pelo fato de que liderança é percebida cada vez mais como um importante fator para impulsionar o aumento do patrimônio da companhia, baseado em ativos intangíveis, e, assim, sua competitividade.

\section{Referencial teórico}

Apresenta-se, a seguir, uma breve discussão teórica sobre liderança nas organizações, os conceitos de gestão estratégica sobre ativos intangíveis e alguns modelos existentes para essa gestão.

\subsection{Liderança nas organizações}

Há, hoje, estudos sobre liderança que emergiram de cada disciplina com algum tipo de interesse no assunto, como Antropologia, História, Ciências Militares, Pedagogia, Filosofia, Ciência Política, Administração de Empresas, Administração Pública, Psicologia e Sociologia. Deram origem a diferentes teorias sobre liderança, desde a dos traços, focada na personalidade de grandes líderes, passando pelas comportamentais, das contingências, situacionais, das trocas entre líderes e liderados, pelo modelo de participação e liderança, pelas teorias neocarismáticas e transformacionais. Chegou-se, então, a questões como a da inteligência emocional e da formação de equipes. Mais recentemente, foram feitos estudos sobre liderança ética, moral e multicultural (ROBBINS, 2002), sobre a chamada liderança autêntica (AVOLIO e GARDNER, 2005) e sobre a liderança espiritual (FRY, 2005).

Liderança é compreendida neste artigo como a conexão dos atributos dos líderes, ou seja, hábitos, traços de personalidade, competências, comportamentos, estilos, habilidades, valores e caráter com os resultados desejados pela organização (ULRICH et al.,1999). Também é entendida como um processo simultâneo, contínuo e de mútua influência dentro de uma equipe, caracterizado pela emergência de líderes oficiais e não-oficiais (ENSLEY et al., 2006).

Esta pesquisa é baseada em duas teorias que apresentam similaridades entre si. A primeira versa sobre a diferença entre liderança e gerência, proposta por Kotter (1998), e, de forma distinta, por Zalesnik (1998). Segundo os autores, liderança e gestão (ou gerência) são dois sistemas distintos e complementares.

\begin{tabular}{|c|c|}
\hline Liderar & Gerenciar \\
\hline Gestão da mudança. & Gestão da complexidade. \\
\hline Alinhar pessoas com visão e as estratégias. & Organizar e treinar pessoas. \\
\hline Falar com muitas pessoas em todas as direções. & Desenvolver e comunicar planos de ação. \\
\hline Apresentar valores às pessoas. & Selecionar pessoas de acordo com funções. \\
\hline Motivar pessoas. & Decidir sobre delegação de autoridade. \\
\hline Apresentar visão de futuro. & Definir estrutura e hierarquia. \\
\hline Lidar com barreiras à mudança. & Controlar pessoas e solucionar problemas. \\
\hline
\end{tabular}

Fonte: baseado em Kotter, (1998) e Zalesnik, (1998)

Quadro 1 - Comparação de liderança e gerência. 
As organizações precisam estar preparadas para selecionar, nutrir e encorajar pessoas que possam desempenhar as funções do líder, mas deve contar também com gestores (ou gerentes) eficazes, que podem ser os próprios líderes ou outras pessoas.

Liderar volta-se para a concretização da visão e geralmente se dá através do falar com muitas pessoas, sejam elas colaboradores sob a gestão do líder, pares ou superiores hierárquicos. Qualquer um que ajude a implementar a visão ou que queira bloqueá-la é importante. Já a função da gerência é um desafio de desenho e engenharia organizacional de alta complexidade.

Líderes incentivam à constante mudança e adaptação a novos patamares. A maneira gerencial de atuar supõe que pessoas e processos se comportem de forma ordeira e previsível, a fim de executar determinadas rotinas. É nesse nível que a conciliação de práticas de liderança e de gerência é mais difícil e desafiadora.

A outra teoria é a que distingue liderança transformacional e transacional proposta por Bass a partir de 1985 e consolidada por Bass e Avolio (2001), baseada em trabalhos de Burns (1979). Liderança transformacional é definida como uma atuação que amplia e eleva os interesses dos colaboradores, gerando consciência e aceitação da missão e propósitos do grupo e conduzindo os colaboradores a olhar além de seus interesses próprios.

Transformacionais são atitudes ligadas à consideração individualizada (atitudes de coaching e mentoring), estímulo intelectual para a resolução autônoma de problemas, motivação inspiracional oferecendo senso de direção e visão e carisma ou influência idealizada. Transacionais são aquelas atitudes que envolvem recompensas contingentes, gerenciamento por exceção ativa ou passiva e a eventual ausência de liderança, em que se observa o laissez faire (deixar correr), presente em casos em que os líderes evitam assumir responsabilidades, tomar decisões e são ausentes quando necessários (ROBBINS, 2002).

Há considerável material que demonstra que o uso da liderança transformacional é associado empiricamente à satisfação dos subordinados, comprometimento profissional e afetivo com a organização, confiança nos gestores e melhor performance na execução de tarefas (KELLOWAY et al., 2000; ZHU et al., 2005). Os mesmos autores citam também estudos que estabelecem elos causais entre liderança transformacional e resultados financeiros de unidades de negócios.

Pode-se notar considerável similaridade entre a teoria da liderança e da gerência proposta por Kotter (1998) e da liderança transformacional em relação à transacional de Bass (1990) e Bass e Avolio (2001). Ambas mostram atitudes voltadas para que sejam atingidos padrões e recompensa por lidar com alta complexidade como gerenciais ou transacionais e aquelas de superação e de mudança como de liderança ou transformacionais.

\subsection{Gestão estratégica de ativos intangíveis e sua relação com a liderança}

Estratégia é o caminho que uma empresa deve seguir. Envolve decisões no sentido de satisfazer as necessidades para as quais a empresa existe e para alcançar os resultados financeiros desejados. Essas decisões devem ser consideradas estratégicas quando for difícil voltar atrás uma vez tomadas (ALMEIDA, 2007).

A busca por inclusão do conceito de liderança organizacional na gestão estratégica de empresas remonta aos anos 1980 e início dos 1990, quando muitos gestores na Europa e América foram expostos ao conceito de Qualidade Total e a uma clara percepção da necessidade de focar nas necessidades e desejos dos clientes como uma forma de manter vantagem competitiva. Gestores e estudiosos acadêmicos observaram que companhias de sucesso, tanto na Europa quanto na Ásia, confiavam mais em critérios não financeiros de performance do que as dos 
países anglo-saxônicos, passando, então, a rejeitar medidas de performance apenas financeiras (LETZA, 1996).

Apesar de não haver consenso sobre como definir, categorizar e medir ativos intangíveis, incluindo-os nas reflexões e práticas estratégicas das empresas, há vários modelos que apresentam distintas soluções para o problema. Essas iniciativas serviram para encorajar organizações a compreender e tornar mais palpáveis conceitos como a liderança (MARR e ADAMS, 2004).

\subsection{Modelos de gestão estratégica de ativos intangíveis}

A seguir são apresentados alguns dos principais modelos que buscam tornar mensuráveis ativos intangíveis, entre eles a liderança.

\subsubsection{Intelectual Capital (IC)}

Foi durante os anos 1990 e em especial na Europa que as referências ao conceito de Capital Intelectual se intensificaram. No âmbito da controladoria, ocorria a busca por demonstrações contábeis que incluíssem ativos intangíveis e, no âmbito da estratégia, o desenvolvimento de planos de ação que levassem esses fatores em conta (BONTIS, 2001).

Vários modelos foram criados entre 1996 e 1997, cada um deles com uma conceitualização diferente do que seja Capital Intelectual. Houve uma convergência para um sistema referencial para o Capital Intelectual chamado de MERITUM Guidelines, desenvolvido entre 1998 e 2002 por um consórcio de pesquisadores de seis países europeus e dirigidos pela professora Paloma Sánchez, da Universidade de Madrid. Esse modelo recomenda classificar os diferentes recursos e atividades intangíveis, bem como os indicadores correspondentes sob três categorias (GUÍMON, 2002):

- capital humano: o conhecimento que os empregados levam para casa ao fim do dia, ao deixarem a empresa. Inclui o conhecimento, as habilidades, a experiência e criatividade das pessoas. Compreende, portanto, os componentes comportamentais que o empregado coloca em seu trabalho e a sua habilidade para contribuir com inovação e melhoria contínua;

- capital estrutural: o conhecimento que fica na empresa quando os empregados saem ao fim da jornada. Compreende rotinas, procedimentos, processos, sistemas, bases de dados e a cultura e subculturas organizacionais;

- capital relacional: todos os recursos e riquezas ligados a relacionamentos de parte da empresa com o ambiente externo, como aqueles com clientes, investidores, credores, fornecedores, intermediários etc., compreendendo também as percepções que essas partes têm da companhia.

\subsubsection{EFQM Excellence Model}

A European Foundation for Quality Management instituiu, em 1992, um prêmio, para cuja parametrização foi criado um scoring que divide os aspectos a serem medidos em fatores facilitadores ou possibilitadores, com $50 \%$ do peso, e resultados, com outros $50 \%$. Todos esses aspectos são ponderados no modelo, e a liderança aparece como o principal facilitador, com peso de 10\% e influenciando os outros três, a saber: Gestão de Pessoas, Políticas e Estratégias, Recursos e Processos, cada um com peso de $10 \%$. Liderança é, no modelo, tudo o que se relaciona com o comportamento dos gestores em todos os níveis hierárquicos no sentido de desenvolver e explicitar uma visão voltada para a Qualidade Total e Melhoria Contínua (WONGRASSAMEE et al., 2003).

Rev. Adm. UfSM, Santa Maria, v. I, N. 1, P. 7-25, Jan./ABr. 2008 


\subsubsection{Skandia Navigator}

O modelo dessa companhia de seguros escandinava, criado no âmbito da discussão sobre Capital Intelectual, deve ser destacado por ela ter sido a primeira grande empresa a fazer um esforço realmente coerente para desenvolver e medir seus ativos intangíveis. Isso foi feito por meio de um sistema dinâmico e holístico de medição, com cinco focos: o financeiro, o do cliente, o dos processos, o da renovação e desenvolvimento e o foco no capital humano, que aparece como figura central no modelo. Neste modelo, dentro do foco no capital humano, aparece pela primeira vez a menção específica a um "Índice de Liderança" (BONTIS, 2001).

\subsubsection{Performance Prism}

Este modelo parte do princípio de que as medidas de performance não devem ser ditadas pelas estratégias e sim pelos interesses e necessidades dos stakeholders. Encoraja as organizações a responder questões ligadas a quem eles são, que estratégias, processos e competência devem ser adotadas para os satisfazer e o que se deve esperar deles em retorno.

Colocar a satisfação dos stakeholders no centro do modelo é o que permite às organizações construir mapas de sucesso abrangentes e compreensivos (NEELY et al., 2003), passo necessário para aprimorar a liderança na organização, através de desenvolvimento de gestores.

\subsubsection{Balanced Scorecard (BSC)}

Esta ferramenta integrativa sugerida por Kaplan e Norton (2004a) tem o objetivo de encorajar e facilitar aos gestores o uso de informação não financeira, mantendo nexo e relações causais claras entre esta e aspectos financeiros, com métricas e controles norteados por considerações estratégicas (LAWRIE e COBBOLD, 2004).

Os próprios idealizadores do BSC reconhecem (KAPLAN e NORTON, 2004b) que a perspectiva chamada de Crescimento e Inovação é o ponto fraco da ferramenta e que poucas organizações conseguiram desenvolver métricas de performance de alto significado e relevância estratégica para este aspecto do BSC. É neste aspecto da ferramenta que se insere a perspectiva da liderança, e os autores consideram uma força de trabalho motivada e bem preparada como o principal gerador dos resultados de uma organização.

\subsection{Ferramentas de medição e gestão da liderança}

A seguir são apresentados dois modelos voltados especificamente para responder à mesma questão sobre a mensurabilidade da liderança organizacional, um deles desenvolvido por uma grande empresa e outro no âmbito acadêmico:

\subsubsection{GE Leadership Effectiveness Survey (LES)}

Durante um encontro anual da General Electric, o CEO Jack Welch afirmou que os líderes na GE seriam considerados responsáveis por "fazer os números", ou seja, vendas, geração de caixa, lucros, participação e ranking em mercados etc., mas também "viver os valores", conceito menos claro para todos os presentes (ULRICH et al., 1999). Os líderes da GE 
desenharam e apresentaram uma ferramenta de mensuração pragmática, conhecida como o LES. O modelo da GE considera que líderes devem ter compromisso individual e capacidade organizacional, transformando direcionamento da empresa em diretrizes, visão em prática e propósito em processos.

Os líderes são avaliados quanto a uma série de quesitos - pessoais e interpessoais, internos e externos - tais como: a) Visão; b) Foco na Qualidade; c) Integridade; d) Compromisso e Responsabilidade; e) Comunicação e Influência; f) Compartilhamento e Abertura; g) Construção de Equipes; h) Conhecimento e Intelecto; i) Iniciativa e Velocidade; j) Pensamento Global. Cada um desses critérios se subdivide em quatro ou cinco fatores de desempenho, aos quais são atribuídas as notas antes mencionadas.

A aplicação se dá utilizando técnicas de feedback de 360 graus, cruzando autoavaliação com a avaliação de subordinados, pares e superiores hierárquicos em relação a dez quesitos, cada um com quatro critérios.

\subsubsection{Multifactor Leadership Questionnaire (MLQ)}

O MLQ é baseado no modelo de liderança desenvolvido por Bass (1990) e Bass e Avolio (2001). Trata-se de uma pesquisa compreensiva ligada a estilos de liderança, que tem como objetivo determinar o grau em que líderes exibem estilos ligados à liderança transacional ou transformacional e estabelecer o quanto os seguidores estão satisfeitos com seu líder e sua efetividade.

O modelo avalia o que se convencionou chamar de "alcance pleno" (full range) de liderança e parte de atitudes consideradas como de "não liderança", como evitar problemas e se ausentar quando a presença é necessária, passa por atitudes chamadas de transacionais, como monitorar erros e recompensar por acertos, até chegar nas atitudes de liderança consideradas como transformacionais. Estas são a construção de confiança, escuta atenta de pessoas, inspiração de outros, encorajamento à iniciativa e ação com integridade. A aplicação também se dá através de avaliação cruzada, e o questionário é oferecido por consultorias externas e aplicado pela Internet ou Intranet.

\section{Caracterização da organização estudada}

A pesquisa foi conduzida de março a outubro de 2006 em uma seguradora multinacional operando no Brasil. A organização vive um momento de forte crescimento, tanto endógeno quanto por meio de aquisições, tendo seu volume de vendas aumentado de R $\$ 250$ milhões, em 1996, para uma estimativa de R \$2,5 bilhões em 2007. Esse aumento de faturamento foi acompanhado por um significativo aumento de quadro de pessoal no mesmo período, que passou de 400 colaboradores para os atuais 2.200 (dados de julho de 2007).

A área de Gestão de Desenvolvimento e Performance colocou à disposição da pesquisa o material usado na primeira turma do programa de desenvolvimento de líderes, em 2002, e o da turma que estava se submetendo ao treinamento no momento da realização da pesquisa, durante todo o segundo semestre de 2006. O programa atual é composto de quatro módulos, com doze encontros, nos quais se enfocam temas como: Traços dos Líderes, Gestão da Mudança (Módulo 1), Conceito de Competências, em especial "Construção de Relacionamentos, Gestão e Liderança de Equipes, Influência, Gerenciamento de Conflitos, Análise e Solução de Problemas, Preocupação pela Ordem e Qualidade e Uso e Difusão do Conhecimento" (Módulo 2). Estuda-se também, no Módulo 3 do programa atual, o conceito de 
Competências do Negócio, Visão, Missão, Valores e Planejamento Estratégico entre outros. Um quarto módulo é dedicado à formação e desenvolvimento de equipes, e a sua continuidade se dá através de um programa de aplicabilidade.

A organização utiliza uma ferramenta de gestão de desempenho recentemente implantada e similar a um BSC. Objetivos permanentes se desdobram em objetivos por grandes áreas e planos de ação para unidades de negócios pequenas. Ainda não há relação direta entre esta ferramenta e uma outra utilizada para a de gestão do desempenho de pessoas, mas o objetivo é uni-las no futuro. Hoje a avaliação de desempenho é feita através de uma ferramenta que possui critérios facilmente mensuráveis, como metas de vendas ou padrões de erros aceitáveis. Há também uma outra com uma parte mais comportamental que mal é usada pelos gestores e praticamente desconsiderada para efeito de avaliação, promoção e premiação.

A organização possui os seguintes níveis hierárquicos: Presidente, Vice-Presidentes, Diretores, Gerentes e equipe operacional. Possui um código de ética e conduta que prevê, entre outras coisas, o tratamento cordial dos colaboradores por parte de seus gestores e proibições de atitudes de assédio de qualquer tipo.

As conversas iniciais com a Diretoria de Recursos Humanos e área de Gestão de Desenvolvimento e Performance de Pessoas mostraram que não havia clareza sobre qual o conceito de liderança prevalecia na organização. Reconheceu-se que, às vezes, a palavra era usada para designar os chefes hierárquicos e, em outras ocasiões, as pessoas que provocavam mudança na organização, independente do cargo.

\section{Metodologia}

Nos estudos sobre administração, nem sempre é tomado o mesmo cuidado com a explicitação sobre a metodologia como a que é tomada com o referencial teórico (GIL, 2003). Hunt (2004) propõe que, em se tratando de liderança, há necessidade de se apresentar as perspectivas éticas, epistemológicas e metodológicas. Estas nos falam sobre o que vamos estudar, como chegamos a saber aquilo que sabemos e a quem interessa o conhecimento obtido.

Em termos éticos, deve ser explicitado que a pesquisa era de interesse da organização, sem ter caráter consultivo. A pesquisa não foi remunerada nem visava claramente a nenhuma mudança ou transformação organizacional. A área de Recursos Humanos da organização aproveitou o interesse do pesquisador no tema pesquisa e aceitou que ela fosse realizada, com a condição de ser mantida a par dos resultados. Esta área tinha forte interesse na pesquisa, em especial para compreender a possível influência que o Programa de Desenvolvimento Líderes possa ter sobre os treinandos e como isso influencia a percepção destes sobre a liderança. Essa preocupação foi inserida nas perguntas de pesquisa, para atender aos objetivos organizacionais e garantir maior riqueza de dados (DUNNING-LEWIS, 2004).

Em termos epistemológicos, deve-se registrar, conforme Dasborough (2006), que estudos qualitativos sobre liderança são relativamente raros. No entanto, são os mais adequados para estudos que se estendem por períodos de tempo maiores, como o caso desta pesquisa, e que tem por objetivo se aprofundar em um "ninho" de fenômenos no qual se insere o conceito da liderança (CONGER, 1998), de extrema sensitividade a contexto (BRYMAN et al., 1996). 


\section{1 Métodos}

Esta pesquisa foi realizada como um estudo de caso único. Na situação específica desta pesquisa, é uma forma válida de abordagem, uma vez que o fenômeno da liderança e o contexto em que ele ocorre, ou seja, a organização em que se desenvolveu a pesquisa, não são possíveis de serem separados e observados distintivamente. A natureza é exploratória, uma vez que o objetivo é proporcionar visão geral acerca da ligação entre liderança e modelos de gestão de ativos intangíveis, com o objetivo de, no futuro, formular hipóteses mais precisas (GIL, 2006).

Alvez-Mazzotti (2006, p. 650) sintetiza o pensamento dos autores Yin (2005) e Stake (2000) afirmando que apesar das divergências entre os autores, parece haver acordo sobre o fato de que o estudo de caso qualitativo "constitui uma investigação de uma unidade específica, situada em seu contexto, selecionada segundo critérios predeterminados e, utilizando múltiplas fontes de dados, que se propõe a oferecer uma visão holística do fenômeno estudado". Nesse caso, a unidade específica é a questão da mensurabilidade da liderança na organização estudada e sua inserção no planejamento estratégico.

Apesar da opção mais desejável ser a de mencionar o nome real da organização e pessoas envolvidas, nesse caso não foi possível, pois a permissão só foi dada caso não houvesse menção a assuntos estratégicos. Como estratégia é foco da pesquisa, a escolha foi por manter a empresa no anonimato.

Foi criado um protocolo para permitir um planejamento da pesquisa e para orientála quando em campo. A estratégia utilizada para a etapa de coleta de dados foi a de seguir as proposições teóricas acima apresentadas para a orientação das entrevistas abertas e formulação das semi-estruturadas. Esse procedimento ajuda, conforme Yin (2005), a colocar foco em certos dados e ignorar outros.

\subsection{Técnicas}

Seguindo as sugestões de Gil (2006), foram realizadas três entrevistas abertas, mas focalizadas e em profundidade com pessoas-chave para compreensão dos temas liderança e estratégia, a Diretora Corporativa de RH, a Gerente de Desenvolvimento e Performance e um Diretor Executivo. Essas entrevistas foram gravadas e transcritas, para possibilitar maior clareza na análise.

Foi utilizada também a observação participante do autor da pesquisa, que, na época, trabalhava na organização estudada. Essa técnica foi utilizada não apenas nas reuniões de que participou, mas também se refere às observações feitas em conversas informais com colegas e nas entrevistas abertas acima mencionadas.

Nas entrevistas, foi solicitado aos três participantes que respondessem perguntas sobre o conceito de liderança na organização, qual o papel do líder em relação à estratégia organizacional e se o conceito de liderança estava de alguma forma ligada à questão do BSC da organização. Durante as entrevistas foram explicitados os construtos teóricos sobre liderança e gerência e sobre liderança transformacional e transacional, verificando se eles têm alguma relação com a compreensão vigente na organização e com as ações que estão em andamento. Foram também observadas e anotadas reações a comentários do autor da pesquisa.

Ainda conforme a proposta metodológica de Gil (2006), foram realizadas 24 entrevistas face a face por pautas com gestores de nível médio da organização. Foram entrevistados doze gerentes internos (administrativos), de um total de 75, e doze gerentes de sucursais externas (comerciais), de um total de 80. Esses dois grupos foram novamente divididos entre 
colaboradores que haviam feito o programa de líderes e outros que não, de forma igual (seis de cada). O objetivo dessas entrevistas era entender se, na compreensão desses gestores, questões estratégicas eram relevantes no seu dia a dia. O foco das pautas era identificar se preponderava uma atuação que pode ser considerada como de um líder ou apenas gerencial e se prevalecia uma atitude transacional ou transformacional.

Foram também analisados o material do programa de líderes e outros documentos internos, como e-mails e cartas do presidente a toda a equipe, que, aliados à observação participante do autor da pesquisa, complementam a necessária multiplicidade de evidências.

\section{Análise dos dados}

A análise dos dados se deu mediante uma estratégia analítica geral, comparando as evidências obtidas com o referencial teórico que deu origem ao plano de coleta de informações, conforme Yin (2005).

\subsection{Percepção da diretora de recursos humanos}

Esta entrevista durou 45 minutos e revelou uma forte pressão por parte da presidência para que fossem desenvolvidas métricas de performance para a atuação da área de $\mathrm{RH}$, que fossem além das tradicionais medidas de retenção de colaboradores ou de adequação dos programas de seleção. A questão da liderança é latente, pois estava, na mesma época, sendo desenvolvido um trabalho de identificação de competências necessárias para os gestores, visando, no futuro próximo, a construção de sistemas de contratação e avaliação de desempenho baseado nelas.

Foi solicitado, durante a entrevista, o acesso ao mapa de competências, feito por consultoria internacional considerada como referência em Recursos Humanos. Vários aspectos do Mapa de Competências causaram surpresa quando comparados com o referencial teórico e com o próprio dia-a-dia da organização. A pesquisa perguntou, por exemplo, por que liderar mudanças não era uma função gerencial, se era dada tanta ênfase ao tema no treinamento de líderes, cujo público-alvo era exatamente este. A resposta foi esquiva, com uma afirmação de que "as competências necessárias haviam sido mapeadas pelos superiores hierárquicos dos gerentes".

Outra pergunta foi sobre o fato de os gerentes não precisarem da competência de liderar equipes, uma vez que todos eles têm equipes de 5 a 25 pessoas sob sua liderança. De novo a resposta não foi clara, com a afirmação de que "não dá para colocar todas as competências para todos".

No mapa ilustrado no Quadro 2, as áreas em cinza não são consideradas necessárias para os cargos em questão, e os números se referem ao fator de importância, sendo 4 o maior. 


\begin{tabular}{|c|c|c|c|c|c|c|}
\hline Cluster & Competências & $\begin{array}{l}\text { Presidente } \\
\text { e VP }\end{array}$ & Diretores & Gerentes & Coorden & Operacion \\
\hline \multirow{6}{*}{ Negócio } & Atuação estratégica & 4 & 4 & 2 & 1 & \\
\hline & Superar resultados & 4 & 3 & 3 & 2 & 1 \\
\hline & Atuação sinérgica & 4 & 4 & 3 & 3 & 1 \\
\hline & Liderar mudanças & 4 & 3 & & & \\
\hline & Foco no cliente & 4 & 4 & 3 & 2 & 1 \\
\hline & Entendimento da organização & & & & 2 & 1 \\
\hline \multirow{8}{*}{ Função } & Construção de relacionamentos & 4 & 4 & & & \\
\hline & Gerenciar pessoas & 4 & 3 & 3 & & \\
\hline & Gerenciamento de conflitos & 4 & 4 & & & \\
\hline & Análise e solução de problemas & & & 3 & & \\
\hline & Liderar equipes & & & & 3 & \\
\hline & Uso e difusão do conhecimento & & & 3 & 3 & \\
\hline & Influenciar pessoas & & & 3 & 2 & \\
\hline & $\begin{array}{l}\text { Preocupação com ordem e } \\
\text { qualidade }\end{array}$ & & & 4 & 3 & \\
\hline \multirow{6}{*}{ Indivíduo } & Autoconfiança & & & 2 & & \\
\hline & Autodesenvolvimento & & & & & 2 \\
\hline & Autocontrole & 3 & 3 & & & \\
\hline & Adaptabilidade & & & 3 & 2 & 1 \\
\hline & Respeito pelas pessoas & 4 & 4 & 3 & 3 & 2 \\
\hline & Iniciativa & & & 4 & 4 & 2 \\
\hline
\end{tabular}

Mapa de Competências fornecido pela área de Recursos Humanos.

Quadro 2 - Mapa de competências da organização.

Durante a entrevista, o autor da pesquisa comentou que alguns aspectos que podem ser considerados como de liderança, segundo o referencial teórico, tais como liderar equipes, uso e difusão do conhecimento e influência não constavam das competências esperadas de Presidente, Vice-Presidente e Diretores. A resposta que foi dada é que era considerado óbvio que estes deviam ter tais conhecimentos, habilidades e atitudes, não sendo necessário, dessa forma, listá-las nem desenvolvê-las. Outro aspecto considerado como pouco claro foi o de os gerentes terem a competência com pontuação máxima e não terem a de liderar equipes nem de liderar mudanças.

Nesta entrevista, ficou claro que a maioria dos elementos considerados por Kotter (1998) como características de liderança está presente no modelo de competências. No entanto, são exatamente estes que a Diretoria de RH tinha mais dificuldade de definir como seriam medidos e ponderados para fins de avaliação e desenvolvimento das pessoas, não havendo critérios claros para eles.

Perguntada sobre se hoje há alguma forma de verificação sobre a aderência da atuação dos gestores no sentido de alinhar as pessoas com as estratégias organizacionais, a Diretora reconheceu que isto só se dá de forma intuitiva e que a maior parte, senão todas, as métricas presentes no plano estratégico e sua ferramenta de controle são ligadas a questões facilmente mensuráveis. Por exemplo, na área de Recursos Humanos, os objetivos são os tradicionais, ligados a turn-over, tempo de contratação, controle do sistema de gestão de desempenho. Reconheceu que na própria área de gestão de pessoas não há ações e tentativas de desenvolver métricas para verificar se a visão, missão e valores da empresa são divulgados e compreendidos.

Da conversa, depreende-se que a função da área de Recursos Humanos hoje é muito mais a considerada por Kotter (1998) como de gerência, no sentido de definir estrutura e hierarquia, selecionar de acordo com funções e treinar pessoas, como antes mencionado. 


\subsection{Percepção da gerência de desenvolvimento e performance}

Esta entrevista teve 60 minutos de duração. Pelos depoimentos, ficou claro que a gerente responsável pela área não acredita que liderança seja algo mensurável. Reconheceu que uma das grandes ênfases do programa de desenvolvimento de líderes é a questão da mudança, tanto de crenças e paradigmas pessoais quanto organizacionais, mas que, no trabalho de competências, isso não está previsto exatamente no nível hierárquico para o qual o programa é voltado. Sua definição de liderança é similar à utilizada no referencial teórico, sendo considerado um líder aquele capaz de motivar sua equipe e, além disso, influenciar pessoas na organização para que esta se aprimore e aprenda continuamente.

Foi possível perceber, pela entrevista, que a dificuldade maior dessa área é a de definição de métricas, e que a crença de que aspectos ligados à liderança não podem ser medidos provém dessa barreira. Hoje, na organização, não há nenhuma tentativa de, por exemplo, identificar os colaboradores que sobressaíram no programa de líderes e verificar sua performance antes e depois do programa. Também não há acompanhamento de propostas de mudança organizacional nem nenhum canal para que tais mudanças sejam propostas que não passem pela hierarquia institucionalizada. A Gerente de Desenvolvimento e Performance reconheceu, na entrevista, que boas idéias podem ser perdidas por não serem consideradas prioritárias pelos Diretores.

Fato é que a Gerência em questão reconhece que a ausência de qualquer ferramenta para medir o retorno sobre o investimento feito no programa de desenvolvimento de líderes dificulta o diálogo com áreas de controladoria e finanças da organização, bem como a defesa da manutenção do mesmo. O que há hoje é uma definição intuitiva de que o programa é importante, partindo dos depoimentos dos participantes ao fim do programa e da alta motivação que eles mostraram durante as oito semanas em que participam do programa.

Confrontada com o referencial teórico sobre liderança e gerência, a Gerente reconheceu que alinhar pessoas com as estratégias da organização e realizar a gestão da mudança é algo que a área de Recursos Humanos tem como objetivo, mas não formulado como plano de ação com métricas próprias na ferramenta de controle de gestão.

\subsection{Percepção de um dos vice-presidentes}

Entrevista com 45 minutos de duração, na qual o ponto mais relevante debatido foi o peso que a presidência da empresa dá à questão estratégica e que todas as ações e recursos da companhia sejam alocados a partir de reflexões estratégicas. Esse vice-presidente entende como fundamental que o posicionamento estratégico seja divulgado para toda a estrutura e que os líderes sejam responsáveis pela execução do projeto, com ênfase na execução. Afirmou textualmente que "entre executar mal uma excelente estratégia ou executar bem uma estratégia razoável, deve-se ficar com a segunda opção". Outra citação textual é a de que: "O principal papel do líder é atuar como um radar. Agregar o conhecimento de toda equipe, ouvir, inteirarse de debilidades e fraquezas, detectar como é o meio ambiente e como ele afeta os projetos", ou seja, pensar estrategicamente.

Pode-se identificar, nas afirmações acima, elementos da liderança chamada de transformacional por Bass e Avolio (2001), como a questão de ouvir a equipe atentamente, bem como elementos chamados de atitudes de liderança por Kotter (1998), como o alinhamento estratégico. Não houve na entrevista, no entanto, nenhuma menção à propagação da visão de futuro da organização, ficando uma impressão que o que se espera do líder é a execução 
das estratégias e um ouvir no sentido de identificar desvios de regras, atitudes meramente transacionais.

Em outro trecho da entrevista, afirmou que o planejamento estratégico deve ser compartilhado por todos para que boas idéias sejam aproveitadas. Afirmou também que os "líderes" estão muito voltados para o operacional. Nesse caso, nota-se que a palavra foi usada claramente no sentido de chefia e que corresponde, no referencial teórico de Kotter (1998), ao que é chamado de gerência. Perguntado sobre o que é esperado do líder na companhia, afirmou que o líder deve sair a "campo de guerra", questionar, extrair as possibilidades com ampla possibilidade de utilização, divulgar e impulsionar a divulgação das estratégias. Sobre o tema de como esta atitude dos líderes em si deveria ser incluída no planejamento estratégico, afirmou que acreditava que o programa de treinamento de líderes deveria continuar e se aprofundar, mas que seria imprescindível desenvolver métricas para a avaliação de desempenho que não fossem apenas baseadas em atingir metas de vendas para os gerentes de sucursal e padrões de qualidade para os gerentes internos. Mostrou também não ter nenhuma idéia de como isto poderia ser feito, afirmando que deve ser uma função do RH e deveria ser incluído no projeto de competências.

\subsection{Percepção dos gerentes de nível médio}

As entrevistas com os gerentes também foram de 60 minutos cada, mas o tempo inicial para se ganhar a confiança era maior, pois ficava claro que havia certa indecisão sobre como as informações prestadas seriam passadas adiante. $\mathrm{O}$ anonimato de todos os respondentes foi garantido e, após esse momento de "quebrar o gelo", todas as entrevistas foram consideradas como aproveitáveis. Percebeu-se, no entanto, que nesse nível da organização havia resistências ao uso do gravador, em razão disso, apenas foram tomadas notas, conforme sugerido por Yin (2005).

Para evitar perda de dados, optou-se por utilizar quatro perguntas padrão, com o objetivo de observar o que esses gestores acreditavam ser mais importante no seu dia-a-dia. Vale notar que as perguntas (Quadro 3) foram organizadas de tal forma que, em alguns aspectos ligados à liderança ou liderança transformacional, ficavam no início da pergunta (Perguntas 2 e 3) e em outras foi colocado no início o aspecto ligado à gerência ou liderança transacional. Pediuse aos gerentes que se posicionassem dizendo se uma das duas opções era mais importante ou se eram igualmente importantes.

O objetivo da pesquisa, aqui, não foi obter percepções sobre liderança com rigor estatístico, mas compreender melhor como os gerentes se posicionavam e se compreendiam os temas propostos, o que aconteceu sempre, sem maiores necessidades de explicação. O resultado obtido está exposto no Quadro 3. 
Quadro 3 - Perguntas e Respostas dos Gerentes.

No seu dia a dia é mais importante: (Alinhar)

(1) organizar e treinar pessoas (Treinar) ou as alinhar com as estratégias da organização

(2) prover senso de direção (Direção) ou planejar como metas são atingidas (Metas)

(3) iniciar e manter esforços para a mudança (Mudança) ou gerenciar processos para que estes sejam estáveis (Processos)

(4) fazer e acompanhar planos de ação e orçamentos (Planos) ou oferecer à equipe uma visão e uma missão focada em resultados (Missão Visão).

\begin{tabular}{|c|c|c|c|}
\hline Gerentes Internos & & & \\
\hline Pergunta 1 & Alinhar & Treinar & Igual \\
\hline Com curso de liderança & 3 & 2 & 1 \\
\hline Sem curso de liderança & 2 & 3 & 1 \\
\hline Pergunta 2 & Direção & Metas & Igual \\
\hline Com curso de liderança & 3 & 1 & 2 \\
\hline Sem curso de liderança & 1 & 2 & 3 \\
\hline Pergunta 3 & Mudança & Processos & Igual \\
\hline Com curso de liderança & 6 & 0 & 0 \\
\hline Sem curso de liderança & 1 & 3 & 2 \\
\hline Pergunta 4 & Missão Visão & Planos & Igual \\
\hline Com curso de liderança & 4 & 2 & 0 \\
\hline Sem curso de liderança & 2 & 4 & 0 \\
\hline \multicolumn{4}{|l|}{ Gerentes de Sucursal } \\
\hline Pergunta 1 & Alinhar & Treinar & Igual \\
\hline Com curso de liderança & 2 & 1 & 3 \\
\hline Sem curso de liderança & 3 & 3 & \\
\hline Pergunta 2 & Direção & Metas & Igual \\
\hline Com curso de liderança & 4 & 0 & 2 \\
\hline Sem curso de liderança & 1 & 3 & 2 \\
\hline Pergunta 3 & Mudança & Processos & Igual \\
\hline Com curso de liderança & 3 & 2 & 1 \\
\hline Sem curso de liderança & 2 & 3 & 1 \\
\hline Pergunta 4 & Missão Visão & Planos & Igual \\
\hline Com curso de liderança & 5 & 0 & 1 \\
\hline Sem curso de liderança & 3 & 0 & 3 \\
\hline
\end{tabular}

Tabela de respostas colhidas durante as entrevistas.

Destaca-se que quase a unanimidade dos gerentes internos e unanimidade dos gerentes de sucursal que participaram do programa de desenvolvimento de líderes posicionararam-se como se o esforço para a mudança (pergunta 3) fosse mais importante no dia-a-dia do que manter processos estáveis e previsíveis. Por outro lado, os gerentes que não participaram do treinamento de líderes consideram, em sua maioria, como mais importante os aspectos ligados 
apenas à gerência. Além das perguntas, na fase inicial das entrevistas, com um caráter um pouco mais informal, a pesquisa possibilitou observar-se que os gerentes reclamavam muito de que quase todo seu dia-a-dia era voltado para "apagar incêndios", o que contradiz os resultados acima apresentados sobre a igualdade de importância em atitudes de liderança e de gerência.

Quando questionados sobre o grau de influência que eles pensavam ter na organização, quase todos informaram ser limitada, pois se comunicam basicamente com seu chefe hierárquico, só tendo a oportunidade de encontrar seus pares uma vez por ano, o que dificulta o desenvolvimento de novas idéias.

\subsection{Percepção oriunda da observação participante}

Durante as reuniões com as equipes, observava-se, por parte dos Diretores Territoriais, menção às estratégias da organização, mas uma ênfase muito maior às questões ligadas a comunicar resultados e a como alcançar metas comerciais, utilizando, para isso, em torno de $50 \%$ do tempo das reuniões. Um pouco menos da metade do tempo das reuniões, em torno de $40 \%$, era usado para a "venda interna" de novos produtos e para treinamento em produtos já existentes, que também podem ser consideradas atitudes gerenciais. Os 10\% de tempo restante eram destinados a conversas e apresentações que podem ser consideradas, segundo Kotter (1998), motivacionais e de liderança.

Considerando-se que uma das estratégias da companhia é ser generalista, parte da reunião era voltada para a divulgação de novos produtos de diferentes áreas, visando a alinhar pessoas com estratégias organizacionais de vendas. O tom das reuniões, no entanto, denotava sempre características gerenciais, com menções a treinamentos, falta de estabilidade de processos e foco em solução reativa de problemas.

\section{Considerações finais}

Há consenso, hoje, sobre a importância de medir aspectos não financeiros, em especial os ligados a pessoas, no âmbito da gestão estratégica de uma organização. Há também evidências de que a gestão estratégica de pessoas é mais importante para o sucesso e alta performance organizacional do que outros fatores, como ganhos de escala, fusões e aquisições ou estar em mercados de rápido crescimento, como também acredita Pfeffer (1998).

A principal ferramenta utilizada na organização estudada para a gestão estratégica é inspirada em um BSC. Mouritsen et al. (2005) comparam o modelo do BSC e o do Capital Intelectual, suas diferenças e complementaridades: BSC mobiliza os gestores de alto nível, pesquisa o ambiente e cria os elos apropriados entre a cadeia de valor e as iniciativas por ele geradas. A questão é comunicar e explicar a estratégia para os empregados. O sistema proposto pelo Capital Intelectual é um processo, e até certo grau uma empreitada coletiva. No âmbito acadêmico e na prática de muitas organizações, os trabalhos europeus sobre Capital Intelectual são tidos como referência para estudos ligados a ativos intangíveis, devendo ser levados em conta quando se trata de avaliar a questão da liderança. Até porque, aparentemente, inspiraram e orientaram os autores do BSC em seus escritos. Notou-se, no estudo, que a Diretoria de RH e a área de Gestão de Desenvolvimento e Performance de Pessoas têm visões distintas sobre o assunto. A primeira mais gerencial, voltada apenas a se adequar ao que é solicitado no momento organizacional, enquanto a segunda é voltada para o futuro da organização, apostando na formação de líderes-gestores, mesmo sem mecanismos claros de medição.

Competências devem ser executadas de forma heterogênea, e a direção é dada por meio de metáforas e narrativas, que devem ser preenchidas por empregados criativos e 
inteligentes. Criatividade e dedicação não são encontradas apenas nos cargos mais altos da gestão, mas em muitos lugares, se não em toda parte na organização.

É o processo de liderança que permite às unidades menores de negócio unirem-se às maiores, criando uma rede para o constante desenvolvimento e alcance dos objetivos. Sob esta ótica funcional, liderança é um processo como qualquer outro, sobre o qual é legítimo querer ter controle, o que implica em mensuração. Por outro lado, como lembra Wheatley (1999), o que acontece dentro de redes organizacionais são relações humanas, e estas não podem ser mensuradas e pesadas, mas sim registradas, mapeadas e talvez influenciadas. Liderança pode ter um lado que é controle, mas querer controlar tudo, inclusive os líderes e o fenômeno da liderança pode apenas destruir a vitalidade de organizações.

Líderes não precisam ser pessoas carismáticas e bem-falantes. São, em muitos casos, aqueles que simplesmente por meio de sua autenticidade e sinceridade provêem a vida de seus seguidores de sentido e se preocupam com seu bem-estar. Contribuem, assim, para posturas positivas na organização, gerando satisfação e auto-realização. Líderes, independente de seu nível na organização, devem participar da construção da realidade, para que mais facilmente se alinhem com ela e influenciem outros a isso. Por isso mesmo devem participar também dos treinamentos de liderança, para poderem avaliá-los além de medições simplistas. Na organização estudada, isso não foi identificado, pois, a partir de certo nível hierárquico, os gestores indicam seus subordinados para o treinamento, mas não participam.

Por trás de um discurso moderno e que coloca a satisfação de clientes e funcionários em primeiro lugar, encontrou-se uma empresa que hesita em dar liberdade para que novas idéias sejam propostas e provoquem mudanças, como o próprio mapa de competências indica.

Em grupos de alta performance, a liderança deveria ser compartilhada entre os membros do grupo informalmente, independente de hierarquia. No entanto, a metáfora militarista apontada por Morgan (2002) ainda é encontrada na empresa, identificável na prática na expressão "ir a campo de guerra" utilizada por um dos vice-presidentes. Também o depoimento de vários gerentes levanta dúvida sobre o grau de participação e envolvimento dos gestores de nível médio, tratados, muitas vezes, como incapazes de traçar planos e metas e influenciar a visão de futuro da organização.

No mapa de competências imaginado para a organização, não consta que gerentes de médio escalão devam ser agentes de mudança. Esses gerentes foram expostos no treinamento de liderança à idéia de mudança acelerada e de organizações que precisam se adaptar e progredir rapidamente. Talvez influenciados pelo que ouviram no curso, esses gerentes entenderam que já participam da mudança organizacional. Até que ponto isso será permitido em uma organização com foco no custo baixo e, portanto, da estabilidade e eficácia de processos é algo a ser respondido pela própria organização.

Modelos de recrutamento, desenvolvimento e avaliação de pessoas baseados em competências estão em voga, mas não são necessariamente excludentes com o modelo da liderança transformacional. Este último mostra alta correlação com performance organizacional. Autores como Menguc et al. (2007) apontam que liderança transformacional e orientação para o mercado podem ser traduzidas em competências gerenciais de apoio à inovação, diferenciação no mercado e baixo custo e podem ajudar a empresa a alcançar vantagens competitivas e a alavancar métricas organizacionais, mais especificamente as ligadas à eficiência.

Analisando-se o mapa de competências, percebe-se que há um grande enfoque no desenvolvimento de competências para o cargo "Gerentes". As competências relacionadas a pessoas e relacionamentos são mais focadas neste cargo do que no cargo de coordenadores; e em menor proporção para o grupo de diretores, o que sugere que a função liderança tem importância no processo atual da empresa. Tal preocupação e importância refletem-se no 
programa de desenvolvimento elaborado e ministrado para esse grupo e cujo maior enfoque também se localiza no desenvolvimento das competências relacionadas a pessoas. Analisandose o mapa de competências e o programa de treinamento, percebe-se que o foco principal não está no desenvolvimento e alinhamento desse grupo às estratégias do negócio. Esse foco é dado ao grupo de diretores, presidente e vice-presidentes.

Para alinhar o modelo transformacional ao modelo de gestão por competências, é necessário validar o resultado que se espera do grupo de gerentes e coordenadores. Nesse nível impera, na organização, confusão entre ênfase em competências relacionadas ao negócio e performance e a gestão de pessoas como um elemento de importância para efeito de treinamento e desenvolvimento no grupo. Alinhamento do grupo de gerentes e coordenadores à estratégia da empresa e foco nas habilidades de gestão de pessoas deste grupo pode garantir a disseminação dos objetivos estratégicos da estrutura.

Nesse ponto, o treinamento de líderes parece de suma importância. Mesmo sem métricas exatas de performance, cabe aqui a decisão política do líder da organização. Harrison (2005) diz que liderança de setores do mercado é associada com a quebra de padrões tradicionais e com o desafio de práticas aceitas no setor. Pois é a liderança das e nas organizações que precisa apresentar esses elementos como criatividade, intuição, autenticidade, determinação, ousadia, foco em resultados e visão de longo prazo, que nem sempre podem ser obtidos com sistemas de recompensas tradicionais e ferramentas integrativas de performance, sempre restando uma parte ao encorajamento para assumir risco e ao ousar pensar fora da caixa.

\section{Referências bibliográficas}

\section{ALMEIDA, M.I.R. Manual de planejamento} estratégico. São Paulo: Atlas, 2007.

ALVES-MAZZOTTI, A. J. Usos e abusos dos estudos de caso. Cadernos de Pesquisa, São Paulo, v. 26, n. 129, p. 638-651, set./dez. 2006.

AVOLIO, B.; GARDNER W. Authentic leadership development: getting to the root of positive forms of leadership. The Leadership Quarterly, v. 16, n. 3, p. 315-338, 2005.

BASS, B. M. Bass and stogdills handbook of leadership: theory, research and managerial implications. New York: The Free Press, 1990.

BASS, B.M.; AVOLIO, B.J. Manual for the multifactor leadership questionnaire, consulting psychologists press. Palo Alto, CA: Mindgarden, 2001.

BRYMAN, A.; STEPHENS, M; CAMPO, C. The importance of context: qualitative research and the study of leadership. The Leadership Quarterly, v. 7, n. 3, p. 353-370, 2005.
BURNS, J.M. Leadership. New York: Harper \& Row Perennial, 1979.

BONTIS, N. Assessing knowledge assets, a review of the models used to asses intelectual capital.

International Journal of Management Reviews, v. 3, n. 1, p. 41-60, 2001.

BRENNAN, N.; CONNEL, B. Intellectual capital: current issues and policy implications. Journal of Intellectual Capital, v. 1, n. 3, p. 206-240, 2000.

CONGER, J. Qualitative research as the cornerstone methodology for studying leadership. The Leadership Quarterly, v. 9, n. 1, p. 107121, 1998.

DASBOROUGH, M. Cognitive asymetry in employe emotional reactions to leadership behaviors. The Leadership Quarterly, New York: Elsevier, v. 17, n. 2, p. 163-178, 2006.

DUNNING-LEWIS, P. Engagement in management research. Working Paper 39. Lancaster University Management School, 2004. 
ENSLEY, M.; HMIELESKI, K.; PEARCE, C. The importance of vertical and shared leadership within new venture top managemente teams. The Leadership Quarterly, v. 17, n. 3, p. 217231, 2006.

GIL, A.C. Métodos e técnicas de pesquisa social. 5. ed. São Paulo: Atlas, 2006.

O método fenomenológico na pesquisa da administração. Caderno de Pesquisa de PósGraduação IMES, ano 4, n. 8, p. 33-42, 2003.

GUIMÓN, J. Recent European models for intellectual capital management and reporting: a comparative study of the MERITUM and Danish Guidelines. Working Paper. Autonomous University of Madrid, 2002.

FRY, T. Toward a paradigm of spiritual leadership. The Leadership Quarterly, v. 16, n. 5, p. 619622, 2005.

HARRISON, J.S. Administração estratégica de recursos e relacionamentos. Porto Alegre: Bookmann Artmed, 2005.

HUNT, J. What is leadership. In: ANTONAKIS, J.; CIANCIOLO, A.; STERNBERG, R. (Orgs.). The nature of leadership. Thousand Oaks: Sage, 2004.

Leadership: a new synthesis. 2. ed. New York: Sage, 1999.

KAPLAN, R.; NORTON, D. Mapas estratégicos. 3. ed. Rio de Janeiro: Campus, 2004a․

Medindo a prontidão estratégica de ativos intangíveis. Harvard Business Review (versão em português), fev. 2004, p. 38-49, 2004b.

KELLOWAY, K.; BARLING, J.; HELLEUR, J. Enhancing transformational leadership: the roles of training and feedback. Leadership \& Organization Development Journal, v. 21, n. 2, p. 145-149, 2000.

KOTTER, J. What leaders really do. Harvard Business Review on Leadership. Harvard: Harvard Business Press, 1998.

KOUZES, J; POSNER, B. Credibilidade. Rio de Janeiro: Campus, 1994.
LAWRIE G.; COBBOLD, I. Third-generation BSC: evolution of an effective strategic control tool. International Journal of Productivity and Performance Management, v. 53, n. 7, p. 611623, 2004.

LETZA, S. The design and implementation of the BSC: an analysis of three companies in practice. Business Process Re-engineering \& Management Journal, v. 2, n. 3, p. 54-76, 1996. MARR, B.; ADAMS, C. The BSC and intangible assets: similar ideas, unaligned concepts.

Measuring Business Excellence, v. 8, n. 3, p. 18-27, 2004.

MENGUC, B; AUH, S.; SHIH, E. Transformational leadership and market orientation: implications for the implementation of competitive strategies and business unit performance. Journal of Business Research, v. 60, n. 4, p. 314-328, 2007.

MORGAN, G. Imagens da organização. 2. ed. São Paulo: Atlas, 2002.

MOURITSEN, J.; LARSEN, H.; BUKH P. Dealing with the knowledge economy: intellectual capital versus BSC. Journal of Intellectual Capital, v. 6, n. 1, p. 8-27, 2005.

NEELY, A.; MARR, B.; ROOS, G.; PIKE, S.; GUPTA, O. Towards the third generation of performance measurement, Controlling, Heft 3-4, abr. 2003.

PFEFFER, J. The real keys to high performance. Leader to leader, Spring 1998, p. 23-29, 1998.

ROBBINS, S. Comportamento organizacional. 9. ed. São Paulo: Prentice Hall, 2002.

ROOS, G.; ROOS, J. Measuring your company's intellectual performance. Long Range Planning, Special Issue Intelectual Capital, v. 30, n. 3, p. 413-426, 1997.

STAKE, R. E. Case studies. In: DENZIN, N. K.; LINCOLN, Y. S. (Eds.). Handbook of qualitative research. London: Sage, 2000. p. 435-454.

ULRICH, D.; ZENGER, J.; SMALLWOOD, N. Resultsbased leadership. Boston: Harvard Business School Press, 1999. 
WHEATLEY, M. Leadership and the new science. San Francisco: BK, 1999.

WONGRASSAMEE, S.; GARDINER, P.D.; SIMMONS, J.E.L. Performance measurement e tools, BSC and EFQM. Measuring Business Excellence, v. 7, n. 1 p. 14-29, 2003.

WRRIGHT, P.; KROLL, M.J.; PARNELL, J.P. Administração estratégica: conceitos. São Paulo: Atlas. 2000.

YIN, R. Estudo de caso: planejamento e métodos. 3. ed. Porto Alegre: Bookman, 2005.

ZACCARO, S.; KLIMOSKI, R. The nature of organizational leadership, understanding the performance imperatives confronting today's leaders.Digital Book, 2001.
ZALESNIK, A. Managers and leaders, are they different? Harvard Business Review on Leadership. Harvard: Harvard Business Press, 1998.

ZHU, W.; CHEW, I.; SPANGLER, W. CEO transformational leadership and organizational outcomes: the mediating role of human-capitalenhancing human resource management. The Leadership Quarterly, v. 16, n. 1, p. 39-52, 2005. 